\title{
PROIDETEICA
}

Artículos

\section{POLÍTICA Y AUTONOMÍA EN EL PENSAMIENTO DE CORNELIUS CASTORIADIS ${ }^{47}$}

\author{
MÁS ALLÁ DE LA POLIS GRIEGA Y DE LA AUTONOMÍA DE LA VOLUNTAD \\ Politics and Autonomy in the Thought of Cornelius Castoriadis \\ Beyond the Greek Polis and the Autonomy of Will
}

LiLiana Ponce

(UNR, Argentina)

\begin{abstract}
Resumen
Cornelius Castoriadis (1922-1997) es uno de los pensadores más lúcidos de finales del siglo XX, que pretende resignificar el proyecto de autonomía individual y social surgido en la Grecia clásica y retomado en las luchas por la emancipación en el mundo occidental moderno. En este artículo, intentaremos analizar la relación entre política y autonomía propuesta por el autor a partir de la relectura del significado atribuido a las instituciones de la democracia ateniense, a su manera de definir la autonomía y a su conceptualización sobre la historia como un modo específico del "hacer" humano. A nuestro entender, la originalidad del pensamiento de Castoriadis para pensar la filosofía política hoy consiste en anudar el análisis de las coordenadas socio-históricas a una cierta ontología social y política que pretende "pensar de otro modo" la historia y la acción política como "modos de hacer" y "modos de ser" propios del ser humano.
\end{abstract}

Palabras clave: Acción política | Teoría de la Historia | Proyecto de autonomía.

\begin{abstract}
Cornelius Castoriadis (1922-1997) was one of the most insightful thinkers of the end of the 2oth century, who aimed to resignify the project of individual and social autonomy that emerged in classical Greece and reappeared in
\end{abstract}

47. Una versión de este artículo fue presentada en el V COLOQUIO INTERNACIONAL DE FILOSOFÍA POLÍTICA. Nuevas perspectivas socio-políticas. Pensamiento alternativo y democracia, organizado por la Universidad Nacional de Lanús, realizado el 6, 7 y 8 de noviembre de 2013 . 


\title{
PROIFIETEICA
}

\begin{abstract}
Western Europe through the struggles for emancipation. In this article, we will try to analyze the relation between politics and autonomy proposed by the author considering the interpretation of Athenian democracy, the redefinition of autonomy and the conceptualization of history as a specific "mode of doing" of the human being. In our opinion, the originality of Castoriadis' work for the political philosophy today is to connect the socialhistorical domain with a social and political ontology that aims to "think otherwise" history and political action as "modes of doing" and "modes of being" unique to man.
\end{abstract}

Keywords: Political Action | Theory of History | Autonomy Project.

\section{Introducción}

Cornelius Castoriadis (1922-1997) es un pensador radical que pretende resignificar el proyecto de autonomía individual y social surgido en los albores del pensamiento occidental y retomado en las luchas por la emancipación en el mundo moderno. En este artículo, intentaremos analizar la relación entre política y autonomía propuesta por el autor, a partir de la relectura del significado atribuido a las instituciones de la democracia ateniense, a su manera de definir la autonomía y a su conceptualización sobre la historia como un modo específico del "hacer" propio del hombre. A nuestro entender, la originalidad del pensamiento de Castoriadis para pensar la filosofía política hoy consiste en anudar el análisis de las coordenadas socio-históricas a una cierta ontología social y política que pretende "pensar de otro modo" la historia y la acción política en cuanto posibilidades esenciales del ser humano.

\section{La polis griega y la significación de las instituciones de la democracia ateniense}

En primer lugar, analizaremos el sentido atribuido por Castoriadis a las instituciones de la democracia ateniense, considerada como "germen" de un proyecto político de autonomía individual y social (Castoriadis, 1982-1983). Esta afirmación tiene que ver fundamentalmente con la íntima relación que se establece entre el ciudadano y su polis. Según Castoriadis, no hay instituciones 


\section{PROIFIETEICA}

autónomas sin individuos autónomos y a la inversa. Las sociedades autónomas son aquellas que se reconocen como fuentes de las leyes, aquellas que reconocen que las instituciones no provienen de un origen exterior a ellas mismas. Y los individuos autónomos son aquellos que manifiestan la capacidad de "juzgar y decidir" por ellos mismos qué leyes son "las mejores" (en el sentido de las "más justas") y de cambiar/ transformar las instituciones vigentes (sean las leyes que organizan la ciudad, sean los magistrados encargados de gobernar). Por lo demás, la "política" como actividad, no es asunto de "especialistas": en Atenas, los magistrados son elegidos por sorteo o por rotación y sólo cuando es necesario un "saber especializado" (una cierta techné), los magistrados son elegidos entre los "mejores" (Castoriadis, 1989a). Así, por ejemplo: no se trata de consultar los libros sagrados ni de escuchar a un profeta, ni siquiera se trata de consultar el oráculo de Delfos. "Se consulta al oráculo de Delfos para saber cuáles son las acciones que es necesario emprender o no: organizar una expedición, construir una ciudad, elegir dónde edificarla, etc. Pero jamás se ha tenido la idea de preguntarle qué ley establecer...” (Castoriadis, 2004: 56).

De manera que, para Castoriadis, la "creación" de la democracia significa el nacimiento de "la política" como dominio propio de la acción humana (Castoriadis, 1982, 1996). ¿Qué es lo que debemos entender entonces por "política"? Si se entiende por "política" las intrigas de la corte, las maniobras de ciertos grupos por administrar el poder existente o las luchas de los diferentes grupos sociales que defienden sus intereses y sus posiciones, Castoriadis (1989a) considera que eso ha existido siempre y en todas partes (entre los chinos, los indios, e incluso entre los aztecas, por ejemplo). Sin embargo, si "la política" es entendida como la actividad cuyo objetivo es "la institución de la sociedad como tal”, es decir, la acción instituyente cuyo objeto de discusión es la "ciudad justa" o la "ciudad buena", la política es una invención griega, en la medida en que lo que se ha puesto allí en juego es una acción donde el "pueblo" (o la comunidad de ciudadanos) es el encargado de juzgar y decidir qué leyes deben organizar la ciudad (Castoriadis, 2004).

A partir de aquí, es posible derivar dos tipos de cuestiones: a) cuestiones de orden ontológico; b) cuestiones de orden político. Las primeras conciernen a 


\section{PROIFIETEICA}

la "ontología" puesta en juego por los griegos ${ }^{48}$. Castoriadis presenta la tesis según la cual esta primera configuración imaginaria del mundo como "carente de sentido" (a-sensé) y como "por ser" (à-être) es aquello que libera a los griegos y les permite crear instituciones en las cuales son los hombres mismos aquellos que se dictan sus propias normas (auto-nómos). El caos, como materia primordial sobre el cual emerge el cosmos, es el vacío (el abismo) y, al mismo tiempo el des-orden (la ausencia de orden, la ausencia de leyes) que debe ser ordenado para poder pensar, para poder actuar, para poder vivir. Pero este "orden" del mundo humano proviene de las leyes "instituidas" por la comunidad política: en Atenas, la institución de la ley, objeto de la "actividad colectiva" explícita y reflexiva, es el resultado de la deliberación y de la decisión de los ciudadanos (Castoriadis, 2004). En este punto, las consideraciones de orden ontológico se anudan a las consideraciones de orden político: si el universo humano estuviera perfectamente ordenado o si las leyes fueran dictadas por Dios, los dioses o cualquier otra fuente extra-social, no habría lugar para la acción política, puesto que sería absurdo preguntarse qué es una buena ley o cuál es la naturaleza de la justicia.

Entre las instituciones y procedimientos que encarnan este primer esbozo del proyecto de autonomía individual y social, Castoriadis señala: "la rotación, el sorteo, la decisión después de la deliberación de todo el cuerpo político, las elecciones, los tribunales populares" (Castoriadis, 1996: 284). Instituciones y procedimientos que no sólo se basan en el postulado de la igual capacidad de todos a asumir las cargas públicas, sino que son también los componentes de un proceso político educativo, de una paideia activa, destinada a desarrollar entre todos los ciudadanos esas capacidades y a hacer del postulado de la igualdad política una "realidad efectiva" (Castoriadis, 1996).

De este modo, podemos afirmar que la constitución de la polis ateniense como cuerpo político, trajo aparejada la "invención de la política" (Finley, 1976;

48. Recordemos que "Grecia" para Castoriadis, desde el punto de vista cronológico, abarca el período que va desde fines del siglo VIII AC hasta fines del siglo V AC, la derrota de Atenas y, desde el punto de vista espacial, Atenas y el territorio jónico, las islas del Mar Egeo y las costas de Asia Menor. Las ciudades dóricas como Esparta plantean problemas porque siempre han sido oligarquías, aunque formen parte del "mundo griego" no sólo por la lengua y la religión, sino también por la concepción de un mundo instituido políticamente donde la idea de que es la ley (el nómos) lo que regula el comportamiento de los ciudadanos se opone a todo arbitrio de un déspota o de un rey absoluto (Castoriadis, 2008). 


\section{PROIFIETEICA}

Castoriadis, 1982; Vidal-Naquet, 1993) como forma específica de la acción humana que se define por su capacidad de "instituir" las leyes y de interrogarse acerca de la justicia (Castoriadis, 1986). La "política" implica un "modo de hacer" (las instituciones) y un "modo de ser" (ciudadano) que son propios del hombre occidental. Para Castoriadis, lo que está implicado en la praxis democrática ateniense es que los hombres se posicionan como "autores" de sus leyes y, por ende, como "responsables" de lo que sucede en la ciudad. Los ciudadanos actúan (modos de hacer) como autores de las leyes y son (modos de ser) responsables por ellas. Al mismo tiempo, puesto que todo individuo es un "fragmento ambulante de la institución de su sociedad" (Castoriadis, 1981), cada ciudadano "es lo que es" (se define en su propio ser) en correlación con las leyes (=las instituciones) de su ciudad. Por lo tanto, sólo podrá lograr su autonomía en el seno de poleis autónomas, sólo podrá ser libre en el marco de ciudades libres.

\section{La afirmación de la voluntad subjetiva y el proyecto de autonomía}

Como sabemos, en la modernidad aparece un nuevo "modelo" de análisis político (Bobbio, 1986) donde lo que se pone en juego es una nueva antropología política a partir de la cual la relación entre el individuo y la ley se redefine a partir de la conceptualización en torno al Estado. Según Castoriadis (1989a), "los modernos" no han podido dejar de pensar "el Estado" bajo la figura heredada de la monarquía absoluta. Mientras que para "los atenienses" o "los lacedemonios", el "pueblo" (démos) se identifica con el "poder político", para "los modernos", "el Estado" es una entidad que está allí, más allá de nosotros mismos, un poder que es por completo ajeno a los individuos y frente al cual lo único que podemos hacer es rodearlo con "barricadas en papel" (las constituciones) que limitan sus prerrogativas (Castoriadis, 1989a). De este modo, en esta nueva relación entre el "individuo" y el "Estado" la ley estará pensada en términos de exterioridad (Hobbes, Leviathán, 1651) o en términos de expresividad (Rousseau, Contrato social, 1762). Esto significa que, o bien la ley coarta el libre arbitrio subjetivo (Hobbes), o bien la ley expresa (y en cierto 


\section{PROIFIETEICA}

modo "encarna") la autonomía de la voluntad (Rousseau).

En el primer caso, el ciudadano aparece como "súbdito". Para Hobbes, la generación de un Estado implica conferir todo el poder y la fortaleza de cada uno de los individuos libres e iguales "a un hombre o a una asamblea de hombres" de manera que sea posible "reducir" las voluntades individuales a una sola voluntad, sometiendo esas voluntades a la voluntad del "soberano". Una vez suscripto el "pacto", los hombres no pueden ser liberados de su sumisión, ya que el soberano representa (hace presente) su voluntad: el súbdito actúa a través de sus actos y juicios, por lo que, en virtud de la institución de un Estado, todo particular es autor de todo cuanto hace el soberano. El soberano administra, legisla y juzga en vistas a la paz y la defensa de sus súbditos. El poder soberano reina sobre los súbditos (Hobbes, 1651, Segunda Parte, Caps. XVII y XVIII).

En el segundo caso, el ciudadano aparece, al mismo tiempo como "súbdito" y como "soberano". Rousseau (1754) considera todo régimen donde los hombres deben subordinarse a la voluntad de un tercero en términos de despotismo. Este poder arbitrario, punto extremo de la desigualdad, hace que los particulares (desiguales en términos de riqueza) se vuelvan iguales, pero como súbditos, en cuanto ya no tienen "más ley que la voluntad de su señor, ni el señor más regla que sus pasiones" (Rousseau, 1754, II Parte). Rousseau considera que el modo de resolver el problema de la desigualdad consiste en la fundación de un estado político donde el hombre se configure como ciudadano. El Estado político es un espacio donde los hombres pierden su libertad natural para alcanzar su libertad moral o política. A diferencia de la polis griega, este Estado político es una entidad artificial creada para superar las desigualdades que se generan en la sociedad civil. $\mathrm{Y}$ a diferencia de Hobbes, no es un espacio donde los hombres tienen que enajenar su libertad para convertirse en súbditos (= esclavos) de un señor, sino un cuerpo "moral y colectivo" donde los hombres ponen en común su voluntad individual y todo su poder bajo la dirección de una "voluntad general" (Rousseau, 1762, Cap. VI. Del pacto social). Al suscribir el "contrato social", cada individuo se halla comprometido como "miembro del soberano", en cuanto participa en la formación de la voluntad general, y "como súbdito”, ya que debe respetar la ley (Rousseau, 1762, Cap. VII. Del soberano). 


\section{PROIFIETEICA}

Por ello, cada "voluntad individual" se compromete con los demás y consigo misma a reconocer la legitimidad de la ley que emana de la "voluntad general" orientada por el "interés común".

Sin embargo, Rousseau no puede dejar de plantear una tensión que subsiste entre la "voluntad individual" y la "voluntad general" cuando los particulares, actuando como "individuos", tienen una voluntad "contraria" o "disconforme" con la voluntad general (Rousseau, 1762, Cap. VII. Del soberano). En efecto, si los hombres quisieran gozar de sus derechos como ciudadanos sin cumplir las obligaciones que tienen como súbditos, esto llevaría a la ruina del cuerpo político. La constitución del cuerpo colectivo supone la necesidad de buscar la "unidad" de la voluntad. Por lo tanto, aquel que se niegue a obedecer la voluntad general, será obligado a obedecerla y, en este sentido, dirá Rousseau, será obligado a "ser libre" (Rousseau, 1762, Cap. VII. Del soberano).

Puesto que la "voluntad general" se expresa en leyes, y la voluntad sólo es libre en la medida en que el individuo particular obedece la ley que él mismo se ha prescripto, esto significa que ser libre es ser autónomo. Según Rousseau, sólo en el Estado político se le restituye al hombre una forma de la igualdad (la igualdad moral o política) que viene a sustituir la desigualdad física del estado de naturaleza y la desigualdad producida por la sociedad civil. En este sentido, la igualdad es lo único que hace al hombre "dueño de sí mismo", porque el impulso del apetito es "esclavitud" y la obediencia a la ley (nómos) que uno mismo (autós) se ha dictado es "libertad" (Rousseau, 1762, Cap. VIII. Del estado civil). Por lo tanto, cuando los hombres actúan en el espacio privado como "súbditos" obedecen las leyes que ellos mismos se han dictado como "miembros del soberano" en el espacio público, no hacen más que obedecer a su "propia voluntad". Sin embargo, todo esto no alcanza para lograr la "unidad" necesaria de la "voluntad general". Rousseau plantea que será necesario recuperar la dimensión "moral" de la vida política en vistas a mantener la unidad del Estado, donde los sentimientos de sociabilidad son los artículos de fe que permitirán ser un "buen ciudadano" y un "súbdito fiel" (Rousseau, 1762, Cap. VIII, De la religión civil). 


\section{PROIFIETEICA}

En este punto, podríamos preguntarnos por el sentido político de la teoría de Rousseau. Si, dadas las condiciones del verdadero contrato social, se produce una tensión entre la "autonomía" de la voluntad general y la "autonomía" de la voluntad individual, quizás la política como actividad subsiste en la medida en que las contradicciones entre la "voluntad general" y la "voluntad individual" respecto de "lo que es justo" son insuperables/ irreconciliables. Una primera respuesta, la de Rousseau, que apela a una "moral del sentimiento de sociabilidad" y una segunda respuesta, la de Kant (1793), que apela a una "moral" fundada en la autonomía de la voluntad racional (Kant, 1788), permanecen en el interior de la contradicción entre "lo universal" y "lo particular". Será Hegel (1802-1803, 1821) el encargado de resolver las contradicciones a partir de la suposición/demostración que la "voluntad subjetiva" no es sino la expresión de una "voluntad ética" inscripta en el "sistema de la eticidad" propio de un "pueblo" o "nación" (Hegel, 1802-1803).

\section{Castoriadis y la acción política. Subjetividad reflexionante, historia y proyecto de autonomía}

No es este el momento de desarrollar la teoría política de Hegel, a la que hemos hecho una breve referencia en vistas a identificar los términos de la oposición. Lo que nos interesa presentar aquí es la postura de Castoriadis (1982, 1986, 1993, 1998a, 1998b), quien trata de poner en tensión el individualismo moderno de la "autonomía de la voluntad" en vistas a resignificar el "proyecto de autonomía individual y social" surgido como germen en la Antigua Grecia. A nuestro entender, el proyecto político de Castoriadis se inscribe en el marco de una nueva antropología política que pretende recuperar, a fines del siglo XX, por un lado, el "germen" de la democracia ateniense como modo del vivir-juntos en la fundación de un espacio común, el espacio público y, por otro lado, la autonomía de la voluntad moderna, más allá del individualismo y de la "retirada" al conformismo de los individuos en las democracias contemporáneas (Castoriadis, 1993). 


\section{PROIFIETEICA}

Castoriadis aclara: "No se trata... de descubrir en una razón inmutable una ley que se daría de una vez y para siempre, sino de interrogarse sobre la ley y sus fundamentos, y de no permanecer fascinados por esta interrogación, sino de hacer y de instituir (por ende, de decir). La autonomía es el actuar reflexivo de una razón que se crea en un movimiento sin fin, al mismo tiempo como individual y como social" (Castoriadis, 1988a: 131, el subrayado es nuestro). Pero tampoco se trata de afirmar la figura societal del individuo "autónomo" de la sociedad neoliberal. Según Castoriadis (1989b), en la "época del conformismo generalizado" no se necesitan individuos "autónomos", sino individuos subordinados a la fuerza de una historia autorregulada y autocontrolada en la que no intervienen "individualidades" capaces de instituir nuevas formas societales. La "autonomía" entendida como la capacidad de los individuos y de las sociedades de darse un "destino" propio, de afirmar su "poder instituyente", es una noción política que los discursos neoliberales acerca de la democracia creen haber superado (Castoriadis, 1989b).

Castoriadis propone entonces la figura de una "subjetividad reflexiva y deliberante" capaz de reconocerse como "actor" y "responsable" de los procesos históricos. Para él, el pasaje del «individuo autónomo" del siglo XVIII al "individualismo" contemporáneo implica una traslación de sentido y un peligroso desplazamiento hacia la apatía social y política donde la tendencia a "reforzar el individualismo" no tiene por efecto acrecentar los valores de responsabilidad y de reflexión, sino acrecentar la "alienación" (que podríamos entender en términos de "heteronomía") del individuo y el desconocimiento de sí mismo como "actor de la historia" 49.

Cuando el pensamiento y la acción política se reducen a simple "aparato matemático" y "técnica de administración" de las relaciones de poder, no hay lugar para la crítica o el pensamiento divergente. Lo que parece un "triunfo" de la "racionalidad objetiva" no es más que la sumisión al "formalismo lógico" y la pérdida del lugar eminente de la subjetividad singular y libre frente al imperio de la masificación y la despersonalización anónima (Castoriadis, 1998a). Esto no significa que Castoriadis pretenda volver a la vieja noción del hombre como

49Para una crítica del individualismo contemporáneo y de los discursos neoliberales ver: Castoriadis (1993, 1998 a, 1998b). 


\section{PROIFIETEICA}

"dueño de sí mismo". Por el contrario, desde su lugar de psicoanalista, Castoriadis recupera el carácter inconsciente de los procesos que posibilitan la configuración de las subjetividades. En este punto, Castoriadis pretende tender un puente entre "psicoanálisis" y "política". A su entender, el fin del análisis consiste en "liberar a los hombres" para hacer la "verdadera política". El imperativo freudiano (Wo Es war, soll Ich werden) hace del análisis una auténtica praxis: una actividad que "prepara a los hombres para la actividad política, los libera para hacerlos capaces de construir esa libertad" (Castoriadis, 1989c), una actividad que permitirá la instauración de una subjetividad que dejará de ser una máquina pseudoracional y socialmente adaptada y que reconocerá y liberará la imaginación radical que se encuentra en el núcleo de la psyché (Castoriadis, 1989c).

Para Castoriadis, un individuo autónomo es un individuo "lúcido" respecto de su deseo y de la realidad, responsable de sus actos, un individuo que puede hacerse cargo de lo que hace (Castoriadis, 1985). Del mismo modo, un pueblo, una comunidad política, también es responsable de lo que ella misma hace. Así, en una entrevista que le hicieron para la televisión griega en 1994,

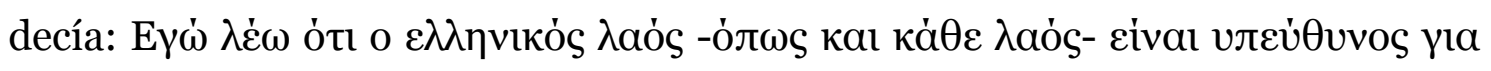

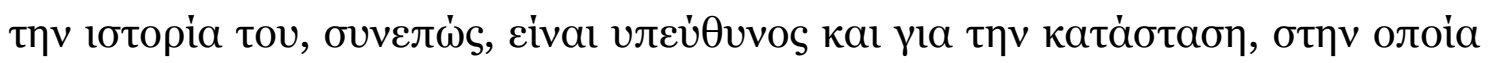

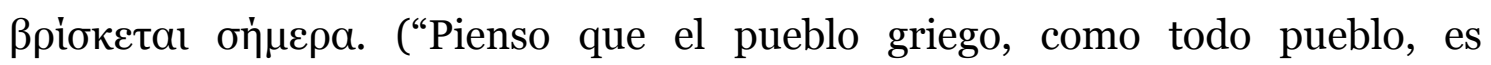
responsable de su historia y, por lo tanto es responsable de la situación en la que se encuentra hoy".) También subraya que la situación en la que se encuentra el pueblo griego no es demasiado diferente de la mayoría de los pueblos de Europa, donde "la más reciente de las catástrofes es evidentemente la invasión

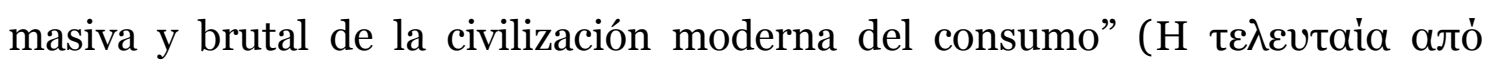

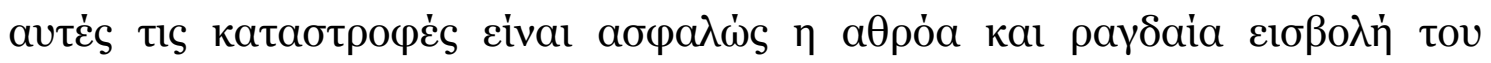

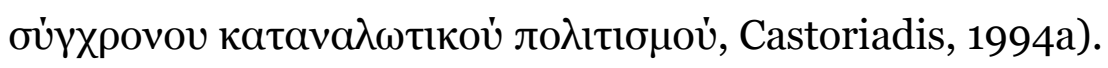

De modo que el tipo de individuo del mundo occidental ya no es un tipo de individuo que lucha por mayor libertad, sino un tipo de individuo que se ha vuelto "privatizado", esto es, que está encerrado en su pequeño medio ambiente personal y que se ha vuelto "cínico" en relación a la política. Como vemos, Castoriadis parece estar atravesado por el "sueño racionalista" de la "conciencia 


\section{PROIFIETEICA}

de sí". A su entender, en la actualidad, decir que un individuo es "libre" significa que cada uno de nosotros es "libre" en los términos en que está establecido por las "significaciones corrientes". "Se dice: cada individuo es "libre", pero, de hecho, todos reciben pasivamente el único sentido que la institución y el campo social le proponen y le imponen: la tele-consumición, hecha de consumo y televisión, de consumo simulado por la vía de la televisión" (Castoriadis, 1994a p. 248, el subrayado es nuestro). De allí que el individuo sea "libre" en el sentido que se le impone desde las significaciones instituidas, el individuo es libre cuando se afirma en la "privatización" de su vida cotidiana.

Así, hacia fines del siglo XX, en Europa, el individuo "tele-consumidor" es la figura dominante de la individualidad social (Castoriadis, 1998b), un individuo que afirma los "derechos subjetivos" que tiene frente al Estado y frente a los demás ciudadanos (Habermas, 1996). Para Castoriadis, el triunfo de la democracia liberal no debe ser entendido entonces como el triunfo del "individualismo". Por el contrario, el efecto de los movimientos históricos del siglo XX ha sido justamente la "privatización » de la vida cotidiana de los individuos y el triunfo de una "mentalidad capitalista" que implicó la retirada del individuo al conformismo y el retorno de la individualidad sobre sí misma. Los sueños de un "futuro compartido" por todos y de una acción política comprometida con « la humanidad » han dejado su lugar al sueño por mejores condiciones de la vida material del individuo aislado y de su familia.

Frente a esta conceptualización "liberal" de la autonomía, Castoriadis subraya: por un lado, el carácter "emancipatorio" y, por otro lado, el carácter de "proyecto" de la autonomía. Podríamos decir entonces que "autonomía" significa, al menos dos cosas: a) posibilidad de darse a sí mismo la propia ley en el plano individual y reconocimiento de la sociedad como fuente y como origen en el plano social, pero también significa b) auto-creación de la propia historia, puesto que es la historia donde se manifiesta la acción y la creatividad de todos: individuos (hombres, mujeres, obreros, estudiantes) e instituciones.

La historia es una escena en movimiento en la que cada uno no se contenta con adecuarse/conformarse a "la fuerza de los hechos". La historia es el lugar donde se puede "actuar", "hacer". "Actuar" es no ser "actuados" por los 


\section{PROIFIETEICA}

resortes de la Historia con mayúsculas, ni tampoco por la fuerza ineluctable de "lo dado". "Actuar" como actores es poner en obra la capacidad de "instituir", más allá de "lo instituido", nuevas figuras/formas del "hacer social", ejercer nuestro "poder instituyente" a partir de "condiciones dadas". Esto quiere decir que no hay "condiciones de posibilidad" ya dadas de una vez por todas, sino que las "condiciones de posibilidad" de la acción humana dependen de la acción misma. Frente a la creencia en "fuerzas impersonales" y "anónimas" y frente a la "aceptación pasiva" de esta situación, es necesario despertar las potencialidades creativas de los individuos histórico-sociales, el poder instituyente de la colectividad y de los individuos, su poder de instituir nuevas figuras del "vivirjuntos", del "hacer/actuar" y del "decir/pensar" social.

\section{A modo de conclusión}

Podemos entonces deducir de la lectura de Castoriadis una especie de « antropología política » que describe un «tipo » de individuo histórico-social (la subjetividad reflexionante frente a la forma «conformista » del individuo privatizado) que resultaría, en cierto sentido, consustancial a la construcción de una "sociedad autónoma" y que permitiría, al mismo tiempo, redefinir la relación entre el "ciudadano" y la "comunidad política". A nuestro entender, Castoriadis describe la figura del "sujeto político" contemporáneo a partir de la resignificación de la relación "público/privado" dominante en la filosofía política moderna. Para él, no hay individuos aislados y "moralmente" autónomos en el espacio privado que deban recuperar la dimensión "política" de su acción en un espacio público por completo exterior a su propia constitución como "sujetos autónomos": sólo hay individuos inscriptos en una trama social que puede ser ella misma "autónoma" o "heterónoma". El individuo aislado y separado no es más que una "ilusión" de la lógica ensídica (Castoriadis, 1994b) que ha dominado y aún domina el pensamiento occidental.

A nuestro entender, esta antropología política va de la mano de la conceptualización de la política como praxis y de una nueva ontología de lo 


\section{PROIFIETEICA}

social donde los términos "autónomo/heterónomo", "individuo/sociedad" no pueden pensarse sino en el marco de una correlación dialéctica. Desde el punto de vista ontológico, el ser individual se liga a su capacidad de hacer históricosocial. Desde el punto de vista político, el ser ciudadano se liga a su capacidad de participar en las instituciones y en los asuntos de la comunidad política, a sus "modos de hacer" políticos. De este modo, la afirmación del individuo histórico-social no es posible sino como protagonista de su propia historia, la afirmación del sujeto político no es posible sino como constructor del espacio público, la afirmación del "individuo" sólo es posible como materialización de su "poder instituyente" en las instituciones de una sociedad. Esta "dialéctica" de lo individual y de lo social, de lo privado y de lo público, de lo instituido y de lo instituyente, se encuentra en la base de la teoría política propuesta por Castoriadis en términos de "proyecto" de autonomía individual y social, que tiene carácter de "proceso" (inacabado e inacabable) y que en cuanto "proyecto", es un "hacer" y un "hacer-se", un "hacer la historia" y un "hacerse a sí mismo". Para nosotros, esta es la invitación y, al mismo tiempo, la herencia que nos ha dejado Cornelius Castoriadis. $\mid$ |ा

\section{Bibliografía}

CASTORIADIS, C. (1981) « L'imaginaire: la création dans le domaine social historique », en Domaines de l'homme. Les carrefours du labyrinthe II. Paris, Seuil, 1986, p. 272-295.

- (1982-83) 《La polis grecque et la création de la démocratie » en Domaines de l'homme. Carrefours II, Paris, Seuil, 1986.

- (1985) «Institutions premières de la société et institutions secondes » in Figures du pensable, Paris, Seuil, 1999.

- (1989a) "Une leçon de démocratie », Videoconferencia ofrecida a Chris

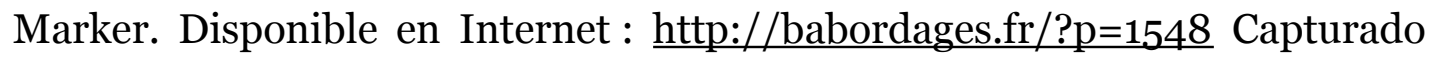
el 26 de septiembre de 2013 .

- (1989b) «L'époque du conformisme généralisé » en Le monde morcelé, Carrefours III, Paris, Seuil, 1990.

- (1989c) «Psychanalyse et Politique » en Le monde morcelé, Carrefours III, 


\section{PROIDIETEICA}

Paris, Seuil, 1990.

- (1993) «La montée de l’insignifiance », Entrevista con Olivier Morel le 18 juin 1993 en La montée de l'insignifiance, Carrefours IV, Paris, Seuil, 1996.

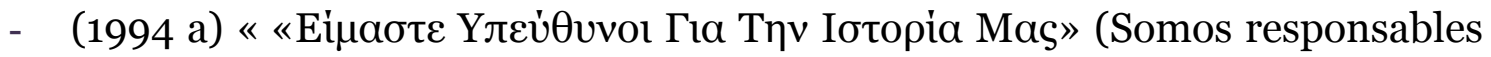
de nuestra historia) Entrevista acordada a la televisión griega, Disponible en: $\quad$ http://marx1deltio.blogspot.com.ar/2015/02/blog-post 21.html. Versión en francés disponible en: https://collectiflieuxcommuns.fr/536considerations-sur-la-grece?lang=fr Capturados el 18 de mayo de 2015.

- (1994b) «Mode d'être et problèmes de la connaissance du socialhistorique » in Figures du pensable. Carrefours VI, Paris, Seuil, 1999.

- (1996) «La democracia como procedimiento y como régimen" en El avance de la insignificancia, Las encrucijadas del laberinto IV, Buenos Aires, Eudeba.

- (1998a) «Stopper la montée de l’insignifiance », Entrevista con Daniel Mermet, en Post-Scriptum sur l'insignifiance. Entretiens avec Daniel Mermet (noviembre 1996). Paris, La Tour d'Aigues: Éditions de l'Aube, 1998.

- (1998b) «De l'autonomie en politique. L’individu privatisé », propos recueillis par Robert Redeker. Le Monde diplomatique, février 1998: p. 23

- (2004) Ce qui fait la Grèce. Tome 1. D'Homère à Héraclite. Séminaires 1982-1983. La Création humaine II. Paris: Éditions du Seuil.

FINLEY, M. I (1976) El mundo de Odiseo. México, FCE.

HEGEL, G.W.F. (1802-1803) El sistema de la eticidad. Trad. Dalmacio Negro Pavón. Madrid, Ed. Nacional, 1983.

- (1821) Principios de la filosofía del derecho. Buenos Aires, Editorial Sudamericana, 1975.

HOBBES, Th. (1651) Leviathán. Universitat de València, 1990.

ROUSSEAU, J. J. (1754) Discurso sobre el origen de la desigualdad entre los hombres. Madrid, 1923

- (1762) Del contrato social. Madrid, Editorial Gredos, 2011

VIDAL-NAQUET, P. (1994) "Una invención griega: la democracia” en Revista

Vuelta, Nro. 209, Abril de 1994, pp. 21-27 